\title{
The linkages between growth, poverty and inequality in Vietnam: An empirical analysis
}

\author{
Hoai Nam Nguyen ${ }^{a}$, Quoc Hoi Le ${ }^{b^{*}}$ and Thi Thu Cuc Nguyena
}

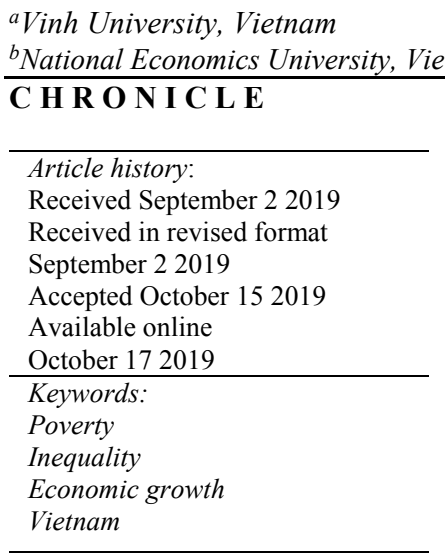

\author{
A B S T R A C T \\ This paper examines how initial inequality and poverty rate are related to subsequent economic growth in the \\ provincial level of Vietnam. The results show a robust negative relationship between initial poverty rate and \\ subsequent economic growth. However, there is no link between initial inequality and subsequent economic \\ growth. The results also show that lower inequality leads to lower poverty rate and poverty reduction could help to \\ reduce inequality. Other determinants of inequality and poverty reduction include human capital, investment, gross \\ domestic product (GDP) growth rate and trade openness. The main policy implication that emerges from this paper \\ is that concentrating on poverty elimination will help us build a more equitable society without sacrificing economic \\ growth.
}

\section{Introduction}

The links between growth, poverty and inequality have long been investigated. Earlier researchers like Lewis (1954) and Kuznets (1955) were primarily interested in the distributional consequences of economic development. In recent years, the reinvigorated interest in the endogenous growth theory has fuelled substantial research into the exploration of the impact of inequality on growth. While the emerging dominant view is that inequality is harmful for growth (Aghion et al., 1999; Perotti, 1993; Persson \& Tabellini, 1994; Alesina \& Rodrick, 1994), some researchers have provided evidence to the contrary (Li \& Zou, 1998; Partridge \& Schwenke, 1997). Theoretically, the channels through which this impact is transmitted differ in accordance with the model used. Reliable empirical testing of these theories has been hampered by the lack of quality data. A number of empirical studies in this field is based primarily on cross-section country data, which suffer from a lack of uniformity. As the countries under consideration are at different stages of economic development, using the available cross-country data to test various hypotheses of the linkages among growth, poverty and inequality does not yield conclusive results. This paper aims to explore how initial inequality and poverty rate are related to subsequent economic growth in provinces of Vietnam. We consider both inequality and poverty as they represent two distinct areas of interest. While the former deals with the dispersion of income in each province, the latter focuses on the lower end of the income distribution. Moreover, many of the theoretical arguments relating inequality to growth are actually better suited to explain the relationship between poverty and growth. Therefore, including both poverty and inequality in the analysis ensures that the separate contributions of these two are related, but distinct factors to economic growth are properly identified. Unlike most other related studies in the literature, this paper analyses a cross-section of provinces rather than countries. While provinces are socio-economic entities in their own right, they

\footnotetext{
* Corresponding author.

E-mail address: hoilq@neu.edu.vn (Q.H. Le)
} 
are particularly relevant for studying the relationship between growth, poverty and inequality since they are less arbitrary spatialeconomic units compared to cross-section of countries, and they represent economies that are at relatively similar stages of development. In addition, as most of the relevant data for provinces are only obtained from the General Statistic Office of Vietnam, the issue of non-uniform methodologies and definition does not pose a serious problem when dealing with provinces (Lan \& Thuong, 2019). Hence, this study on the relationship between income distribution, poverty and growth is more reliable than many of the studies in the literature.

The paper is organized as follows. Section 2 briefly reviews the various existing theories on the mechanisms through which inequality affects economic growth. Section 3 presents the empirical framework used to test the linkages between growth, poverty and inequality. The empirical results are presented in section 4 and 5, and the final section provides concluding remarks.

\section{Theoretical links between poverty, inequality and growth}

The work of Kuznets (1955) is perhaps the starting point for examining the links between poverty, inequality and growth. Kuznets hypothesizes that growth and inequality are related in an inverted U-shaped curve. In the early stages of economic development, inequality increases as a result of the shift of people from the large, relatively poor and egalitarian agricultural sector to the small, industrial sector that is richer but relatively unequal. In the latter stages, however, as a bulk of the population shifts to the urban sector, there is an increase in the relative wages of the poorer workers in both urban and rural sectors, and various policy measures are also implemented to reduce intra- and inter-sectoral inequality. Therefore, overall income inequality in the economy decreases in the latter stages of development. One implication of the Kuznets hypothesis is that if, in early stages, economic growth leads to more inequality, then poverty might take many years to decrease in the developing world.

In recent years, a number of theoretical studies has tried to examine the links between inequality and growth. Rather than focusing on the Kuznets hypothesis, the renavigated interest in the endogenous growth theory has provided substantial research into the exploration of the impact of inequality on growth. Although almost all the studies undertaken on the topic show a negative effect of inequality on growth, the channels through which this effect is transmitted differ in accordance with the model used. There are six main families of models which explore the links between growth and inequality: the political economy model (PE), the capital market imperfection model (CM), the integrated model (INT), the socio-political instability model (PI), the fertility/education issue model (FE), and the social comparisons model (SC). We now turn to briefly review these models. PE model (Alesina \& Rodrik, 1994; Persson \& Tabellini, 1994; Bertola, 1993; Perotti, 1992): This model tries to build a bridge between theories of endogenous growth and theories of endogenous political economy. In democratic societies, the level of taxation is decided by the median voter. Taxation is assumed to be proportional to income, and public expenditure progressive as tax revenues are redistributed lump-sum to everyone. Hence, the benefit received by the poor is greater than the benefits received by the rich. Thus, the poor would prefer a high level of taxation-redistribution. Since in unequal societies the income of the median voter is slower than the mean income, majority rule would dictate a high level of redistribution which in turn discourages investment by depressing its net return and lowers growth. The negative impact of inequality would be attenuated by the degree of wealth bias of the system against the poor. The more a society moves away from the democratic archetype of "one man, one vote", the less it is possible to reduce the level of inequality through redistribution (Hoi et al., 2017).

CM model (Chiu, 1998; Aghion and Bolton, 1997; Galor \& Zeira, 1993; Saint-Paul and Verdier, 1993): This model is based on the role played by imperfections in the capital markets. Specifically, in societies where agents do not have free access to borrowing, inequality implies that a relatively large share of the population is below the threshold cost of education. Therefore, investment in human capital is low, and if growth is enhanced by investment in human capital, growth is low too. Redistribution increases total output and growth because it allows the poor to invest in human capital. If capital markets tend to improve as an economy develops, then the effects related to capital-market imperfections are more important in poor economies than in rich ones. Therefore, the predicted effects of inequality on economic growth would be larger in magnitude for poor economies than for rich ones. It is also noted that the credit market imperfection arguments are actually better suited to explain the relationship between poverty rate and economic growth. While higher inequality does not always imply that a larger fraction of the population is too poor to gain access to credit, a higher poverty rate unambiguously means that more people are creditconstrained. For example, inequality in an economy could be high even though all the people in the economy are relatively well off. Therefore, we should expect a negative relationship between poverty rate and economic growth. INT model (Benabou, 1996): This model provides an integrated framework in which the impact of redistribution on growth is not necessarily linear. There are two opposite effects. Redistribution is good if public expenditure goes to finance education in a world with imperfect capital markets, and bad if it only transfers income from the rich to the poor because it depresses the net return to investment of the rich. Therefore, growth is inverted-U shaped with respect to redistribution and distribution is U-shaped with respect to inequality. PI model (Alesina \& Perotti, 1996; Benhabib \& Rustichini, 1996; Grossman \& Kim, 1996; Canning \& Fay, 1993): This model emphasises the consequence of inequality on political instability and social unrest. According to the PI model, inequality is an important determinant of socio-political instability and this has negative effects on growth through lower expected returns to investment. Specifically, inequality exacerbates social conflict which in turn makes property rights less secure and reduces growth. Moreover, the participation of the poor in crime and other anti-social actions represents a direct waste of resources because the time and energy of the criminals are not devoted to productive efforts. Defensive efforts by 
potential victims represent a further loss of resources.

FE model (Perotti, 1993): According to the FE model, inequality has a negative effect on economic growth through the distortion of the households' decisions on education and fertility. Parents have to optimise the use of the household's resources, alternatively through an improvement in quality (education) or in quantity (fertility) of their offspring. Since education has a cost equal to the income foregone while at school, poor households do not invest in human capital but in the quantity of children. However, growth is only enhanced by investment in human capital, therefore, ceteris paribus, a society in which there is high inequality presents a relatively large number of poor households which invest in quantity rather than education. The high fertility rate of this society leads to low growth. SC model (Knell, 1998): This model is built on the Benabou model (1996), in which individuals make social comparisons. The model is based on the assumption that maximisation of individual utility does not depend solely on own consumption but also on the average consumption of some reference group. In an unequal society, poor households are tempted to conform to the norms and to fulfil social needs and expectations by involving in higher consumption activities and by lowering investment in human capital in order to reduce the gap with rich households. These activities maximise present welfare but go to the detriment of future welfare and growth.

As the above discussion shows, inequality and poverty can affect growth through various mechanisms that often work in opposite directions. It is not possible to predict which mechanisms are dominant by using theory alone. Empirical investigation is therefore the key to understanding the relationship between inequality, poverty and growth.

\section{Empirical framework}

The purpose of the paper is to explore the relationship between initial inequality, poverty and growth at the provincial level of Vietnam. As the previous empirical studies, the following specification is used:

$$
\text { GROWTH }=\beta_{1}+\beta_{2} I N E Q+\cdots+\beta_{i} X_{i}+\varepsilon
$$

where GROWTH is the average growth rate of GDP in a province over the period under consideration, INEQ is a measure of initial inequality, $P O V$ is the rate of poverty and $X$ is a vector of control variables. Poverty rate (POV) is defined as the fraction of people below the poverty line. The poverty line corresponds to the expenditure (including the value of home production and adjusted regional and seasonal price differences) required to purchase $2100 \mathrm{Kcal}$ per person per day using the food basket of households in the third quintile, plus a non-food allowance equal to what households the third quintile spend on non-food items. The perception of inequality depends on the inequality index used. Indices are neither cardinally nor ordinally equivalent and some of them lack basic properties that good indices should have. We take this problem into consideration by running the econometric tests to alternative specifications of the variable INEQ. In this paper, we use two measures of inequality - the GINI coefficient and the ratio of income shares going to the top and bottom quintiles of the population. The GINI coefficient is the most widely used aggregate measure of inequality for the whole population in an economy. It is based on the Lorenz curve, which describes the cumulative distribution of income (or expenditure) as a function of cumulative distribution of households (Cowell, 1995). More specifically, the GINI coefficient is the area above the Lorenz curve and below the diagonal 45 degree line divided by the area under the diagonal line. The Vietnam living standard household survey data (VHLSS) include the number of households in different expenditure ranges and the expenditure of each individual household. Using information about the proportion of people below different levels of per capita expenditure and following Princeton development economist Deaton (1997, 139), the GINI coefficient can be derived as follows:

$$
G=\frac{N+1}{N-1}-\frac{2}{N(N-1) u}\left(\sum_{i=1}^{n} P_{i} X_{i}\right)
$$

where $u$ is mean income of the population, $P_{i}$ is the income rank $P$ of person $i$, with income $X$, such that the richest person receives a rank of 1 and the poorest a rank of $\mathrm{N}$. This effectively gives higher weight to poorer people in the income distribution, which allows the Gini to meet the Transfer Principle. In this paper, inequality of consumption expenditure rather than income is analysed because consumption is considered a better measure of human well-being. Also, relative to the income variable, consumption shows less volatility as it is not so vulnerable to idiosyncratic shocks. According to Deaton (1997), consumption data are less influenced by measurement errors, particularly for rural households. The main drawback of the GINI coefficient is that since it is a measure of aggregate inequality, it fails to completely capture certain changes in the underlying income distribution. Deininger and Squire (1996) recommend reporting information on the income shares by quintiles to overcome this problem. Drawing from their suggestion, we supplement each GINI measure by the corresponding ratio of the total income 
going to the richest and the poorest $20 \%$ (quintiles) of the population. Apart from $I N E Q$ and $P O V$ variables, our vector of control variables follows a standard approach widely used in the literature and includes GDP per capita level (GDPPC) at the beginning of the period (to check for the convergence hypothesis), the average ratio of investment to GDP over the period (INVEST), and a measure of human capital (HUMCAP). The best proxy for the measure of human capital has been considered the average schooling years in the adult population. The other variables taken into consideration such as the enrolment ratio in primary, secondary or higher education can instead be considered as proxies for human capital. Observe that in the above framework, we are studying how the initial values of the independent variables INEQ, POV and GDPPC are related to subsequent GDP growth rate. This framework avoids problems of endogeneity or simultaneity bias associated with these four variables. While it is true that GDPPC can affect subsequent inequality and poverty rate, this is a recursive relation rather than a simultaneous equation relation and hence does not influence the estimation of Eq. (1). While several other variables have been suggested to be linked to growth, we decide to keep the vector of control variables relatively small, in the difficult exercise of balancing the risks of multicollinearity with the risks of omitted variable bias. However, we test the model with several alternative configurations of the controls. The basic model only includes GDPPC, INVEST, and HUMAN. In fact, many of the other variables are found to be highly correlated to GDP, to $H U M A N$, to $P O V$ or to $I N E Q$. The data used in this paper come from the General Statistic Office of Vietnam. The data cover a total of 61 provinces of Vietnam. Data on GDP growth rate, investment, human capital, trade openness, GDP per capita at the provincial level are only available from 1996 to 2014 . Therefore, we are able to examine the relationship between initial inequality, poverty and growth for the period of 1996 to 2014. Data on poverty rate and the GINI coefficient are computed by using data from Vietnam living standard household surveys which were implemented by GSO. The basic statistics of the variables are provided in Table 1 in Appendix. According to the figure in the table, while mean GDP per capita and inequality increased between 1996 and 2014, the poverty rate decreased during this period. Table 2 in Appendix provides the correlation matrix of variables used in this paper. As shown, the correlation of GDP growth rate with independent variables is weak; there is a weak possibility that the signs of these relationships may change when the regression in Eq. (1) is estimated.

\section{Empirical results on the links between poverty, inequality and growth}

The regressions 1, 2 and 3 in Table 1 are based on Eq. (1), but they test the relationship between growth rate of GDP (the dependent variable) and each of the two provincial characteristics under consideration - initial poverty rate and initial inequality - one at a time. All the estimations are performed using OLS with White's correction for heteroscedasticity. Regression 1, which considers only POVRATE 1996, shows a negative and statistically significant relationship between POVRATE 1996 and subsequent GDP growth rate. This implies that provinces with higher initial poverty rate experience slower GDP growth rate. Regressions 2 and 3 in Table 1 show that coefficients on both GINI and TOPBOTTOM are negative, but not significant.

Table 1

The impact of poverty and inequality on growth

\begin{tabular}{lccccc}
\hline Explanatory variable & 1 & 2 & 3 & 4 & 5 \\
\hline POVRATE 1996 & -0.036 & & & -0.039 & -0.037 \\
GINI 1996 & $(0.011)^{* *}$ & & & $(0.01)^{* *}$ & $(0.01)^{* *}$ \\
& & -2.51 & & -3.82 & \\
TOPBOTTOM 1996-2014 & & -3.96 & & -3.91 & -0.085 \\
& & & -0.039 & & -0.17 \\
GDPPC 1996 & 0.002 & 0.003 & -0.17 & & 0.002 \\
& $(0.001)^{*}$ & $(0.001)^{* *}$ & $(0.001)^{* *}$ & $(0.001)^{*}$ & $(0.001)^{* *}$ \\
INVEST 1996-2014 & 0.049 & 0.042 & 0.045 & 0.047 & 0.051 \\
& $(0.01)^{* * *}$ & $(0.01)^{* *}$ & $(0.01)^{* *}$ & $(0.01)^{* * *}$ & $(0.01)^{* *}$ \\
HUMCAP 1996-2014 & 0.073 & 0.056 & 0.061 & 0.07 & 0.07 \\
Intercept & $(0.03)^{* *}$ & $(0.03)^{*}$ & $(0.03)^{*}$ & $(0.03)^{* *}$ & $(0.03)^{* *}$ \\
& 0.38 & 1.34 & 0.29 & 1.89 & 0.13 \\
N & -3.76 & -4.17 & -3.92 & -4.06 & -3.82 \\
R squared & 61 & 61 & 61 & 61 & 61 \\
\hline
\end{tabular}

The dependent variable is the average growth rate of GDP between 1996 and 2014. Standard errors are in parentheses. *, **, and $* * *$ denote significance at $10 \%, 5 \%$ and $1 \%$ level respectively. 
This implies that initial inequality does not affect subsequent economic growth. This can be explained by the fact that there are many opposing mechanisms through which inequality can affect growth. The results presented here indicate that, on the whole, the mechanisms through which inequality leads to higher growth are offset by the opposing mechanisms through which inequality harms growth. Regressions 4 and 5 in Table 1 include variables of all provincial characteristics as independent variables in equation 1. Like the results in regressions 1, 2 and 3, the results in regressions 4 and 5 do not show the relationship between initial inequality and growth, but they support the finding that high poverty rate is negatively associated with subsequent growth rate of GDP. In all the regressions, GDPPC 1996 is positively and significantly related to the subsequent growth rate of GDP. This indicates that on the average, provinces with high initial GDP per capita have a higher GDP growth rate. This result is surprising in that it does not support the theory of conditional convergence among economies (Barro, 1991; Mankiw et al., 1992; Sala-i- Martin, 1996). This can be explained by the fact in Vietnam that during the transition period from a centrally planning economy to a market economy, economic opportunities are embodied by rich provinces with high level of income per capita and resource advantages. As a result, these provinces often sustain higher GDP growth rate than the others. Similarly, the vital role of human capital and investment is shown in all the regressions as the coefficients on HUMCAP 1996-2014 and INVEST 1996-2014 are positive and statistically significant.

\section{Determinants of poverty and inequality}

The previous section sheds light on how initial inequality and poverty rate are related to subsequent GDP growth rate. This section turns to examine the determinants of poverty and inequality in Vietnam. As the previous empirical studies, the following specification is used:

$$
\begin{aligned}
& \text { POVRAETE }_{i}=\delta_{i}+\alpha_{i} X_{i}+e_{i} \\
& \text { INEQUALITY }_{i}=\delta_{i}+\alpha_{i} X_{i}+\varepsilon_{i}
\end{aligned}
$$

where POVRATE $E_{i}$ and INEQUALITY $i$ are the rate of poverty and inequality in province $i$ respectively. $X_{i}$ is vectors of control variables. Our vector of control variables follows a standard approach widely used in the literature and includes the growth rate of GDP per capita level (GDPPC), a measure of initial inequality (INEQ), the ratio of investment to GDP over the period (INVEST), trade openness (OPENNESS) and a measure of human capital (HUMCAP). The best proxy for the measure of human capital has been considered the average schooling years in the adult population. The other variables taken into consideration such as the enrolment ratio in primary, secondary or higher education can instead be considered as proxies for human capital. Trade openness is measured as the ratio of exports and imports to GDP. The perception of inequality depends on the inequality index used. Indices are neither cardinally nor ordinally equivalent and some of them lack basic properties that good indices should have. We take this problem into consideration by running the econometric tests to alternative specifications of the variable INEQ. We use two measures of inequality - the GINI coefficient and the ratio of income shares going to the top and bottom quintiles of the population (TOPBOTTOM).

Table 2

Determinants of poverty

\begin{tabular}{lcc}
\hline Explanatory variable & 1 & 2 \\
\hline GDPPC 1996-2014 & -0.35 & -0.38 \\
& $(0.19)^{*}$ & $(0.20)^{*}$ \\
GINI 1996 & 0.3 & \\
& $(0.18)^{*}$ & 0.58 \\
TOPBOTTOM 1996 & & $(0.28)^{*}$ \\
& & 0.23 \\
INVEST 1996-2014 & 0.23 & $(0.04)^{* * *}$ \\
& $(0.04)^{* * *}$ & -0.11 \\
HUMCAP 1996-2014 & -0.09 & $(0.06)^{*}$ \\
OPENNESS 1996-2014 & $(0.05)^{*}$ & -0.06 \\
& -0.06 & $(0.01)^{* * *}$ \\
Intercept & $(0.01)^{* * *}$ & 14.27 \\
& 5.01 & -8.93 \\
N & -11.02 & 61 \\
R squared & 61 & 0.48 \\
\hline
\end{tabular}


The results in Table 2 show that the coefficient on the growth rate of GDP per capita (GDPPC) is negative and statistically significant in both regressions, and the corresponding standardized coefficient in each case is also larger than the standardized coefficients for most of the other independent variables. Thus, these regressions indicate that a higher growth rate of GDP per capita is associated with lower rate of poverty in the future, a finding that is consistent with the widely held view among economists. The coefficients on the GINI coefficient (GINI) and the ratio of income shares going to the top and bottom quintiles of the population (TOPBOTTOM) are positive and significant. This implies that provinces with a higher level of inequality will have a higher rate of poverty in the future. This result also supports the idea that poverty reduction depends on the level of inequality. Another result of the regressions is that provinces with higher level of human capital and higher level of openness have, on the average, lower end-of-period poverty rate. The positive impact of investment on poverty rate implies that provinces with higher poverty rate have a higher ratio of investment to GDP.

The dependent variable is the rate of poverty in 2014 . Standard errors are in parentheses. $*, * *$, and $* * *$ denote significance at $10 \%, 5 \%$ and $1 \%$ level respectively. The regression results in Table 3 present the determinants of inequality. As shown, the coefficients on GINI 1996 and TOPBOTTOM 1996 are significant and have a standardized value that is much larger than all other standardized coefficients. Thus, initial level of inequality is, by far, the most important determinants of future inequality. Similarly, as we can see from the Table 3, the initial poverty level is clearly the important determinant of end-of-period inequality. Also, as shown in the previous section, higher initial inequality contributes to higher end-of-period poverty. These findings suggest that a reduction in poverty could help reduce future inequality and vice versa. Another finding is that provinces with higher initial GDP per capita have a higher inequality in the future. Trade openness is positively and significantly related to inequality, implying that provinces with higher level of openness have a higher future inequality.

Table 3

Determinants of inequality

\begin{tabular}{lcc}
\hline Explanatory variable & GINI 2014 & TOPBOTTOM 2014 \\
\hline GINI 1996 & 0.23 & 0.18 \\
TOPBOTTOM 1996 & $(0.1)^{* *}$ & $(0.07)^{* *}$ \\
GDP 1996-2014 & & -0.05 \\
& & $(0.05)$ \\
POVRATE 1996 & -0.001 & 0.05 \\
& $(0.001)$ & $(0.02)^{* *}$ \\
INVEST 1996-2014 & 0.16 & 0.001 \\
& $(0.05)^{* * *}$ & $(0.009)$ \\
GDPPC 1996 & 0.01 & 0.001 \\
HUMCAP 1996-2014 & $(0.02)$ & $(0.0005)^{* *}$ \\
OPENNESS 1996-2014 & 0.003 & 0.01 \\
Intercept & $(0.000)^{* *}$ & $(0.01)$ \\
N & 0.10 & -0.03 \\
R & $(0.05)^{* *}$ & 0.56 \\
\hline
\end{tabular}

The dependent variables are GINI 2004 and TOPBOTTOM 2014. Standard errors are in parentheses. *, **, and *** denote significance at $10 \%, 5 \%$ and $1 \%$ level respectively.

\section{Concluding remarks}

This paper has analysed the relationship between growth, poverty and inequality in Vietnam from 1996 to 2014 by using the provincial data and data from household living standard surveys. The most robust result has been the negative association between poverty rate and subsequent GDP growth rate. Moreover, higher initial poverty level leads to higher inequality in the future. The empirical results show no evidence of the relation between inequality and the growth rate of GDP. As discussed in section 4 of the paper, there are a number of arguments we can make to explain the observed relationship. More specifically, there are many opposing mechanisms or channels through which inequality can affect growth. The results presented here 
indicate that, on the whole, the mechanisms through which inequality leads to higher growth are offset by the opposing mechanisms through which inequality harms growth. The next step in gaining a deeper understanding of the inequality-growth relationship would involve isolating and testing these various mechanisms to determine their relative importance to the growth process. Such an undertaking, however, is beyond the scope of this paper, and must be set aside for future research.

Given empirical finding in this paper, we can point out some policy implications. First, it is necessary to point out that no relationship between inequality and GDP growth rate does not mean that redistributive policies are undesirable. But it does imply that when GDP growth is major objective, we should pursue redistributive policies with caution and choose policies that are least distortionary in the economic sense. Second, the results present good news to those who see poverty elimination as an integral part of economic development policy. They indicate that reducing poverty, apart from helping the most vulnerable segments of society, is beneficial from the perspective of improving the future distribution of income and promoting economics growth. In other words, there is definitely no trade-off between poverty reduction and economic growth. Third, the results suggest that lower inequality leads to lower poverty rate and poverty reduction could help to reduce inequality, therefore concentrating on poverty elimination will also help us to build a more equitable society without sacrificing economic growth. Pursuit of anti-poverty policies, therefore, appears to be a very desirable political objective.

\section{Acknowledgement}

The authors would like to thank the anonymous referees for constructive comments on earlier version of this paper.

\section{References}

Aghion, P., \& Bolton, P. (1997). A theory of trickle-down growth and development. The Review of Economic Studies, 64(2), 151-172.

Aghion, P., Caroli, E., \& Garcia-Penalosa, C. (1999). Inequality and economic growth: The perspective of the new growth theories. Journal of Economic literature, 37(4), 1615-1660.

Alesina, A., \& Perotti, R. (1996). Income distribution, political instability, and investment. European economic review, 40(6), $1203-1228$.

Alesina, A., \& Rodrik, D. (1994). Distributive politics and economic growth. The Quarterly Journal of Economics, 109(2), 465490.

Barro, R. (1999). Inequality, growth and investment. NBER working paper, 7038, Massachusetts.

Benabou, R. (1996). Inequality and growth. NBER macroeconomics annual, 11, 11-74.

Benhabib, J., \& Rustichini, A. (1996). Social conflict and growth. Journal of Economic growth, 1(1), $125-142$.

Bertola, G. (1993). Factor shares and savings in endogenous growth. American Economic Review, 83(5).

Canning, D., \& Fay, M. (1993). The effect of infrastructure networks on economic growth. New York: Columbia University, Department of Economics.

Chiu, W. H. (1998). Income inequality, human capital accumulation and economic performance. The Economic Journal, 108(446), 44-59.

Cowell, C. M. (1998). Historical change in vegetation and disturbance on the Georgia Piedmont. The American Midland Naturalist, 140(1), 78-90.

Deaton, A. (1997). The analysis of household surveys: a microeconometric approach to development policy. The World Bank.

Deininger, K., \& Squire, L. (1998). New ways of looking at old issues: inequality and growth. Journal of Development Economics, 57(2), 259-287.

Galor, O., \& Zeira, J. (1993). Income distribution and macroeconomics. The Review of Economic Studies, 60(1), 35-52.

Grossman, H. I., \& Kim, M. (1996). Predation and accumulation. Journal of Economic Growth, 1(3), $333-350$.

Hoi, L.Q., Nam, P.X., \& Tuan, N.A. (2017). An evaluation of provincial macroeconomic performance in Vietnam. Journal of Economics and Development, 19(2), 34 -47.

Knell, M. (1998). Social comparisons, inequality and growth. Mimeo, university of Zurich.

Kuznets, S. (1955). Economic growth and income inequality. The American economic review, 45(1), 1-28.

Lewis, W. A. (1954). Economic development with unlimited supplies of labour. The manchester school, $22(2), 139-191$.

Lan, H.H., \& Thuong, P.T.H. (2019). Financial inclusion and income inequality: Empirical evidence from transition. Economies. Journal of Economics and Development, 21 (special issue), 23-34.

Li, H., \& Zou, H. F. (1998). Income inequality is not harmful for growth: theory and evidence. Review of development economics, 2(3), 318-334.

Partridge, H., \& Schwenke, D. W. (1997). The determination of an accurate isotope dependent potential energy surface for water from extensive ab initio calculations and experimental data. The Journal of Chemical Physics, 106(11), 4618-4639.

Perotti, R. (1993). Political equilibrium, income distribution, and growth. The Review of Economic Studies, 60(4), 755-776.

Persson, T., \& Tabellini, G. (1994). Is inequality harmful for growth?. The American Economic Review, 84(3), 600-621. 
184

Saint-Paul, G., \& Verdier, T. (1993). Education, democracy and growth. Journal of development Economics, $42(2), 399-407$.

Sala-i-Martin, X. X. (1997). I just ran four million regressions (No. w6252). National Bureau of Economic Research.

Vietnam Government Statistic Office, various year, Vietnam Living Standard Survey, Hanoi.

\section{Appendix 1}

The correlation matrix

\begin{tabular}{|c|c|c|c|c|c|c|c|c|c|c|c|}
\hline & $\mathrm{X} 1$ & $\mathrm{X} 2$ & $\mathrm{X} 3$ & $\mathrm{X} 4$ & $\mathrm{X} 5$ & X6 & $\mathrm{X} 7$ & $\mathrm{X} 8$ & X9 & $\mathrm{X} 10$ & $\mathrm{X} 11$ \\
\hline X1: GDP 1996-2004 & 1 & & & & & & & & & & \\
\hline X2: GDPPC 1996 & 0.308 & 1 & & & & & & & & & \\
\hline X3: POVRATE 1996 & -0.2802 & -0.54 & 1 & & & & & & & & \\
\hline X4: POVRATE 2004 & -0.1749 & -0.384 & 0.8199 & 1 & & & & & & & \\
\hline X5: GINI 1996 & -0.0872 & 0.151 & -0.2462 & -0.3144 & 1 & & & & & & \\
\hline X6: GINI 2004 & 0.0228 & 0.127 & 0.305 & 0.3872 & 0.2562 & 1 & & & & & \\
\hline X7: ТОРВОТТОМ 1996 & 0.1626 & 0.31 & -0.1942 & -0.057 & 0.2165 & 0.3331 & 1 & & & & \\
\hline X8: ТОРВОТТОМ 2004 & -0.0367 & 0.306 & 0.01 & 0.137 & 0.2747 & 0.4505 & 0.488 & 1 & & & \\
\hline X9: INVEST 1996-2004 & 0.1933 & -0.252 & 0.2299 & 0.321 & -0.156 & 0.0321 & -0.0115 & -0.1467 & 1 & & \\
\hline $\begin{array}{l}\text { X10: HUMCAP 1996- } \\
2004\end{array}$ & 0.147 & -0.02 & 0.1773 & 0.1913 & -0.1069 & 0.3794 & 0.3144 & 0.2515 & -0.1744 & 1 & \\
\hline $\begin{array}{l}\text { X11: OPENNESS 1996- } \\
2004\end{array}$ & 0.2937 & 0.2 & -0.4004 & -0.3706 & 0.0364 & 0.0938 & 0.1928 & 0.0628 & 0.2353 & 0.026 & 1 \\
\hline
\end{tabular}

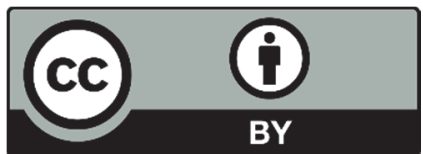

(C) 2019 by the authors; licensee Growing Science, Canada. This is an open access article distributed under the terms and conditions of the Creative Commons Attribution (CC-BY) license (http://creativecommons.org/licenses/by/4.0/). 